\title{
WAYS OF UPDATING THE TECHNOLOGY OF INDUCTION SURFACING OF THIN STEEL DISCS
}

\author{
Ch.V. PULKA, O.N. SHABLY, V.N. BARANOVSKY, V.S. SENCHISHIN and V.Ya. GAVRILYUK \\ Ternopol Ivan Puluj National Technical University \\ 56 Russkaya Str., 46011, Ternopol, Ukraine. E-mail: v_gavryliuk@mail.ru
}

\begin{abstract}
Considered are existing technological schemes of induction surfacing of operating elements of agriculture machines. The best results are provided by continuous induction surfacing using double-loop circular inductor, heat and electromagnetic shields, horizontal vibration and rotation of part being surfaced. Application of developed technological schemes and equipment for induction surfacing of thin disks allows increasing productivity, saving electric energy, improving microstructure, increasing wear resistance and stability of thickness of deposited layer as well as reducing residual stresses and deformations of disks. 16 Ref., 6 Figures.
\end{abstract}

\begin{abstract}
Keywords: induction surfacing, surfacing consumables, surfacing technology, double-loop inductor, heat and electromagnetic shield
\end{abstract}

Induction surfacing is based on heating and melting of filler material under the effect of high-frequency currents [1-3]. This is the most technological process for some types of parts due to simple equipment, easy surfacing process and, as a result, absence of necessity in welders with high qualification. In particular, induction surfacing found the widest distribution in surfacing of operating elements of agricultural and road machines and in some other branches of national economy (Figure 1).

Considering increase of industry demands the method of induction surfacing is continuously improved in the following directions: rise of process efficiency and wear resistance of deposited metal, optimization of induction heating modes, improvement of indictor structures and systems of energy saving in surfacing of disks of random diameters and dimensions of surfacing zone.

The aim of present work lies in analyzing the results of researches in directions mentioned above, improvement of induction surfacing process by example of thin profiling disks of top cutters (Figure 1, $f$ ).

Continuous successive surfacing using segment inductor (Figure 2, $a$ ) is used in production for strengthening of top cutters with solid cutting edge. At that, the inductor is fixed to high frequency generator and part being surfaced is rotated relatively to the inductor.

The advantages of this method are technological flexibility and possibility of surfacing of different diameter parts with comparatively small power. However, this technology has relatively low efficiency and large energy consumption. Besides, the part can be deformed in surfacing, that effects stability of thickness of deposited layer and additional alignment operation is necessary for elimination of disk deformation.

The technology of simultaneous induction surfacing over the whole operating surface using surfacing width more than teeth height and double-loop inductor was proposed for increase of surfacing efficiency of top cutters of saw tooth form (Figure $2, b)$. It resulted in $4-5$ times increase of surfacing efficiency.

Loops in the double-loop circular inductor have opposite phase connection on current and magnetic flow between themselves and with generator. Using such a connection provides for formation of electromagnetic field only in surfacing zone and uniform distribution of temperature over the disk surface, where charge is being melted. However, this technology requires significant expenses of electric energy.

Updating the modes of power supply to inductor [4] was carried out in order to save electric energy. It is shown that simultaneous surfacing of disks over the whole operating surface can be carried out using constant specific power at certain time as well as with its change on exponential law (energy saving mode). At that, 15-25\% economy of electric energy is achieved depending on used surfacing consumables. Thus, for example, surfacing with sormite powder PG-S1 provides for $15 \%$ electric energy saving and that makes $23 \%$ in surfacing using PG-AN9 powder.

Work [5] proposed a calculation procedure for double-loop circular inductor which provides 


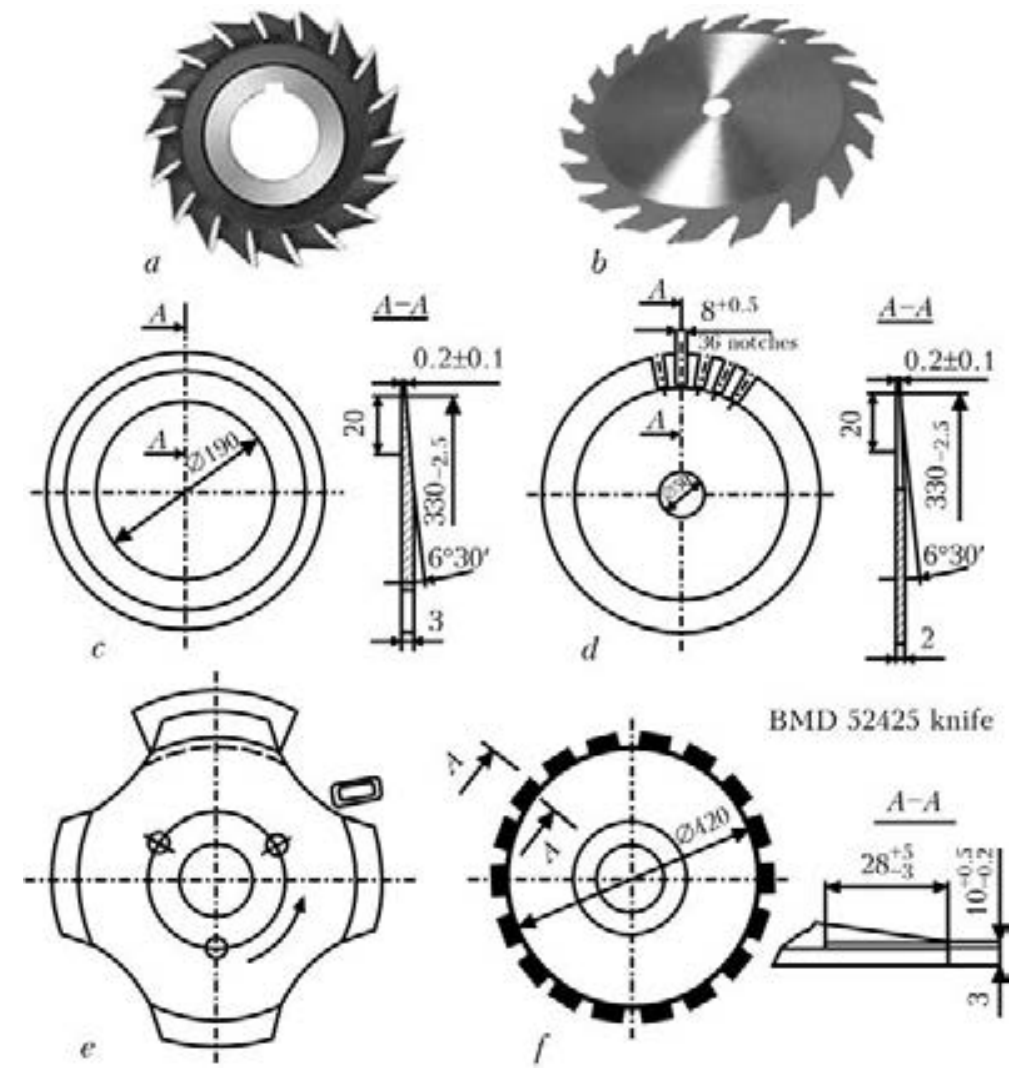

Figure 1. Thin disks subjected to surfacing: $a$ - disk cutter; $b$ - disk saw; $c, d$ - drive and non-drive disks for roofing slate cutting; $e-$ knife for sunflower cutting; $f-$ top cutter BMD 52425

for realizing of methods of simultaneous surfacing of profiling disks of saw tooth form over the whole surface by energy saving mode. A disadvantage of this technology is the fact that it can be used only for disks of specific diameter and surfacing zone width. There are cases on practice when diameters of disks and width of surfacing zone are changed. This requires selecting other structures of inductors or special shields, that is related with large financial and labor expenses.

Investigations and calculations of sizes of inductors and special shields were carried out for different variants of application of these systems, namely, only at inductor use (Figure $3, a$ ); in- ductor and electromagnetic shield (Figure 3, b); inductor, heat and electromagnetic shields ( $\mathrm{Fi}^{-}$ gure $3, c)$ [6-8].

Data received as a result of investigations allowed determining size of inductors and shields as well as current for surfacing of saw tooth disks of random diameter and size of surfacing zone, namely: disks of $210-240 \mathrm{~mm}$ diameter and 2$6 \mathrm{~mm}$ thickness, width and thickness of deposited layer $10-50$ and $1.0-1.5 \mathrm{~mm}$, respectively.

Thus, manufacturing engineer applying one or another heating system of induction surfacing (see Figure 3) selects necessary data graphically or using the tables according to disk diameter,
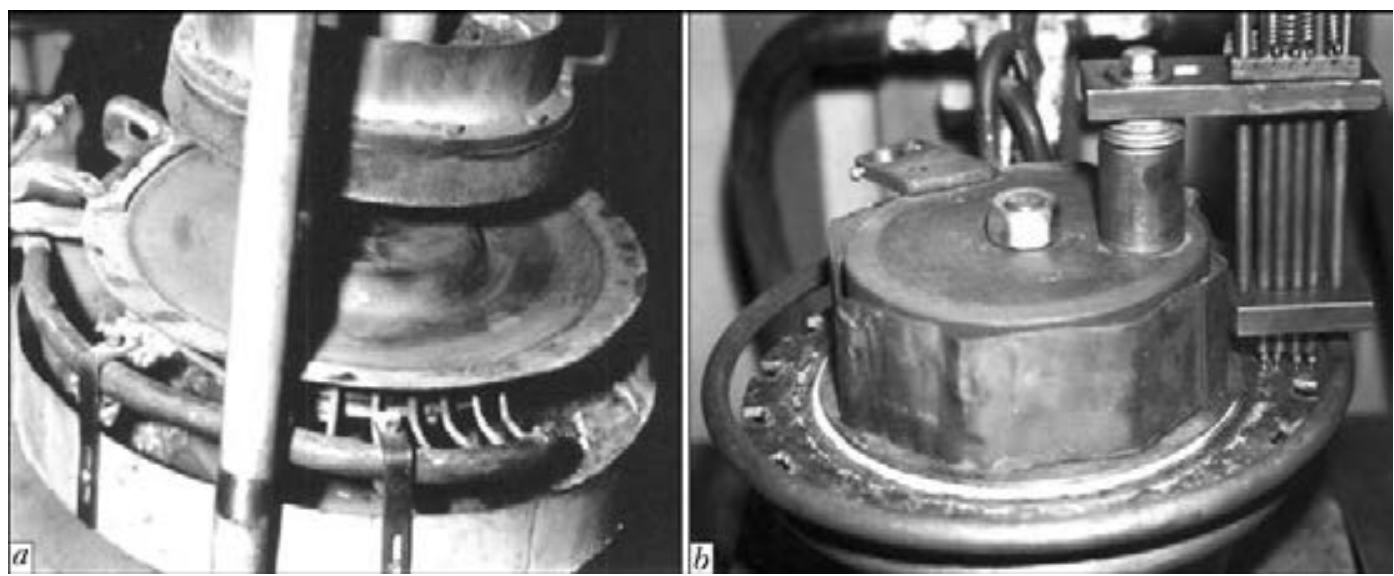

Figure 2. Device for surfacing of all-stamped solid cutter using segment inductor $(a)$ and top cutters of saw tooth form in double-loop circular inductor (b) [3] 

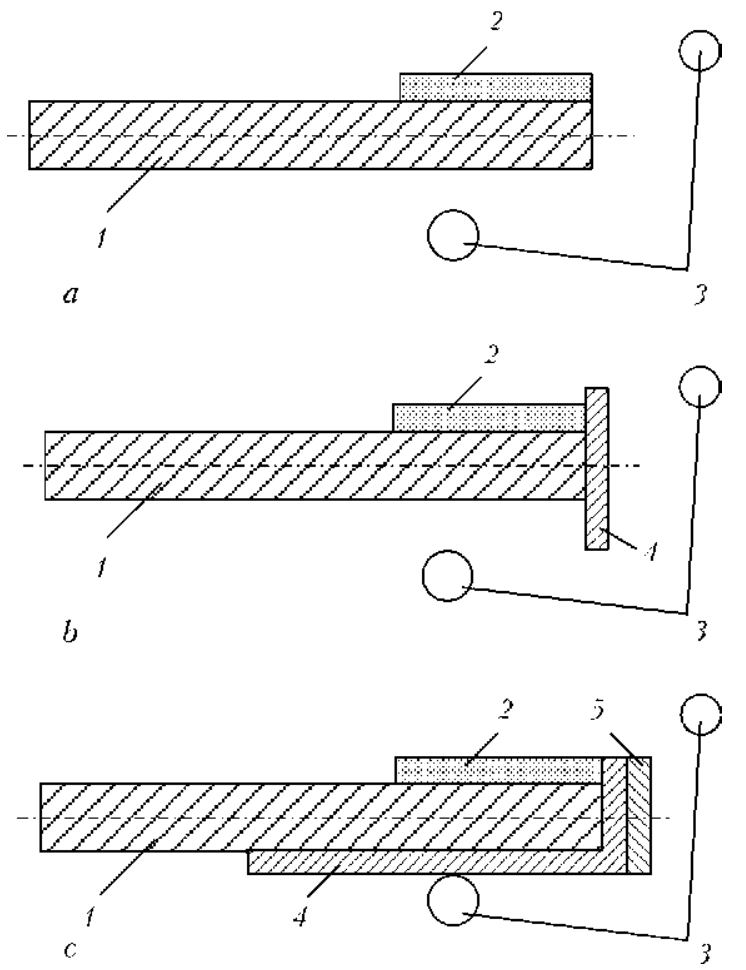

Figure 3. Schemes for positioning inductors and special shields in induction surfacing: $a$ - traditional scheme; $b-$ inductor and electromagnetic shield; $c-$ inductor, heat and electromagnetic shields; 1 - part; 2 - charge; $3-$ double-loop circular indictor; 4 - heat shield; 5 - electromagnetic shield

width and thickness of deposited layer. For example, the first scheme (Figure 3, a) requires entering seven parameters relating inductor structure and its positioning with respect to part, that reduces time and financial expenses for experiment performance and implementation of new technology.

The technology proposed by authors ( $\mathrm{Fi}^{-}$ gure $3, c)$, particularly, allows additional saving of $12-14 \%$ of electric energy, increasing stability of deposited metal by $10-15 \%$ and decreasing disk surfacing time from 32 to $22 \mathrm{~s}$ [9].

Within time a proposal was made about adding new technological operation in induction surfacing process (Figure 4) for further increase of wear resistance of deposited metal. At that, taking into account small thickness of plane disks, significant attention was paid to residual stresses, deformation and displacements which appear after surfacing in zone of operating surface having different width [10-13].

Work [11] represents the results of investigation of effect of additional technological schemes of induction surfacing on stability of deposited layer thickness by four schemes. $90 \%$ of measurements of thickness of deposited layer are in tolerance range at surfacing using scheme in $\mathrm{Fi}$ gure $4, d$, that is $22 \%$ more than in surfacing by
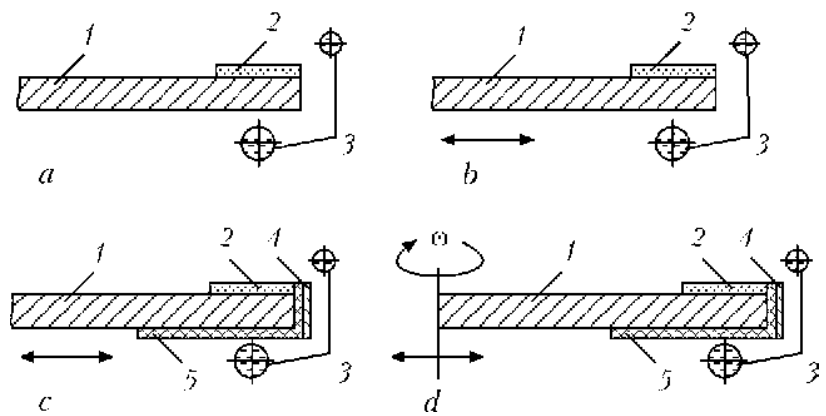

Figure 4. Schemes of induction surfacing used during investigations: $a$ - without vibration of deposited part; $b-$ with horizontal vibration of deposited part; $c-$ with horizontal vibration of deposited part using heat and electromagnetic shields; $d-$ the same, but with additional rotation of deposited part; 1 - part; 2 - deposited layer; 3 circular double-loop inductor; 4,5 - electromagnetic and heat shields, respectively (the arrows show direction of vibration application and disk rotation relatively to vertical axis)

scheme in Figure 4, $a$. In this case more uniform thickness of deposited layer is achieved due to joint application of horizontal vibration, heat and electromagnetic shields as well as centrifugal forces providing uniform distribution of liquid metal in surfacing zone.

The same works show that maximum residual stresses $\sigma_{2}$ appear in the deposited layer directly near the boundary of its joining with the base metal, and $\sigma_{2}=0.54 \sigma_{\mathrm{t}}$ at the boundary with non-surfaced zone at sormite tensile strength $\sigma_{\mathrm{t}} \sim$ $\sim 150 \mathrm{MPa}$ [13].

The developed technology (see Figure 4, $d$ ) allows heating with low level of temperature gradient over disk radius (Figure 5). Horizontal and vertical vibration of the part with corresponding amplitude and frequency directly during surfacing results in deposited metal microstructure optimizing and increasing wear resistance of deposited layer of sormite type (PG-S1 powder) approximately in 1.5 times.

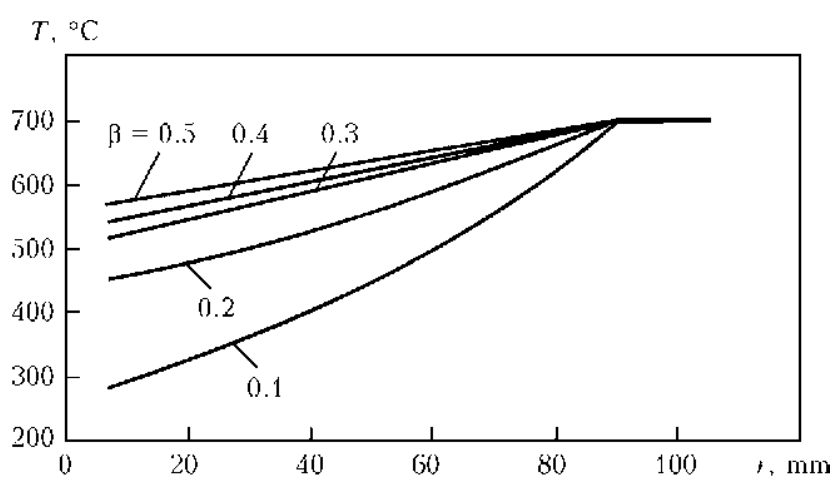

Figure 5. Distribution of temperature over disk radius at the moment of deformation beginning in the base metaldeposited metal system as elastic body at different values of gradient coefficient $\beta$ 


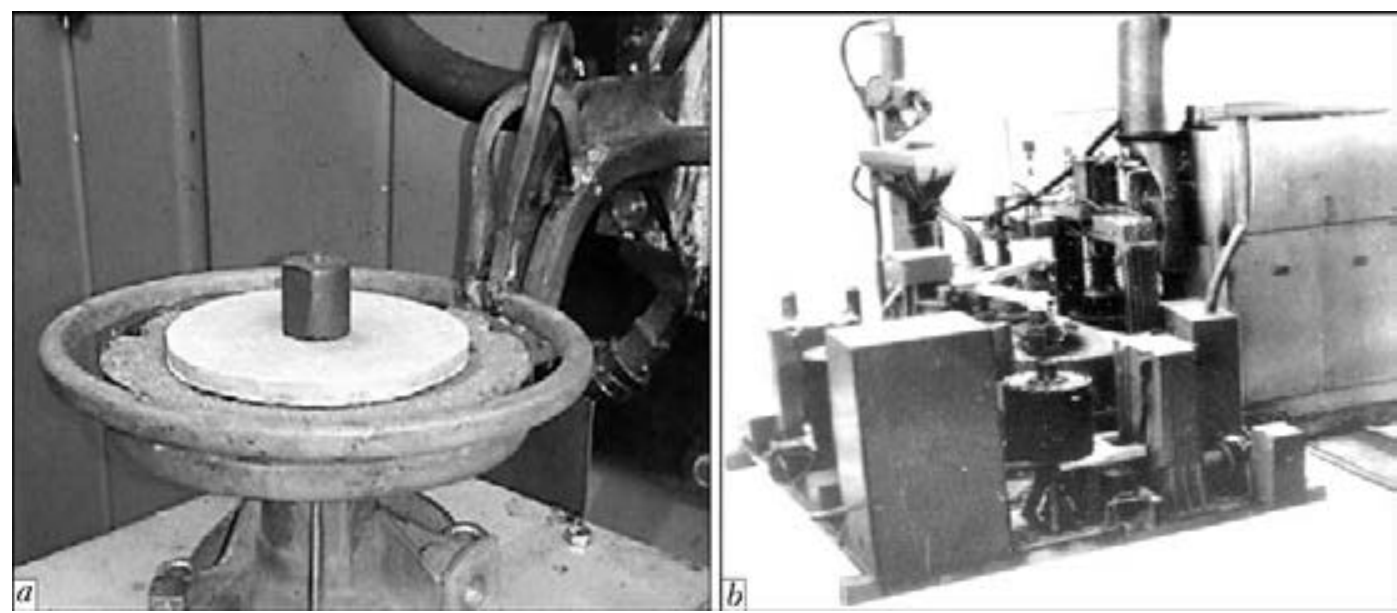

Figure 6. Surfacing unit $(a)$ and automated production system for surfacing of top cutters $(b)$

Automated production system for surfacing of top cutters (Figure 6) [14-16] was developed for realizing these technologies.

High-frequency generators of VChI $63 / 0.44$, VChG 6-60/0.44 and VChG9-60/0.44 of $60 \mathrm{~kW}$ power and $440 \mathrm{kHz}$ frequency were used for induction surfacing since base metal thickness makes $2-6 \mathrm{~mm}$.

Charge consisting of mixture of PG-S1 sormite powder and flux was used as surfacing consumable.

\section{Conclusion}

Application of developed technological schemes and equipment for induction surfacing of thin disks allows increasing efficiency, saving electric energy, improving microstructure, wear resistance and stability of deposited layer as well as decreasing residual stresses and deformations of disks.

1. Tkachev, V.N. (1971) Wear and increase in service life of agricultural machine parts. Moscow: Mashinostroenie.

2. Ryabtsev, I.A., Senchenkov, I.K. (2013) Theory and practice of surfacing works. Kiev: Ekotekhnologiya.

3. Pulka, Ch.V. (2006) Technological and energy effi ciency of induction surfacing of thin steel discs: Syn. of Thesis for Dr. of Techn. Sci. Degree. Kiev.

4. Shably, O.N., Pulka, Ch.V., Budzan, B.P. (1987) Optimization of power inputs in induction surfacing of thin-wall discs. Avtomatich. Svarka, 1, 36-39.

5. Shably, O.N., Pulka, Ch.V., Budzan, B.P. (1988) Ways of energy saving in induction surfacing of thinwall discs. Ibid., 12, 56-58.
6. Shably, O.N., Pulka, Ch.V., Pismenny, A.S. (1997) Optimization of inductor design parameters for induction surfacing of thin steel discs. Ibid., 6, 17-20.

7. Shably, O.N., Pulka, Ch.V., Pismenny, A.S. (2002) Optimization of inductor parameters for uniform heating of discs across the width of hardfacing zone allowing for screening. The Paton Welding J., 11, 23-25.

8. Shably, O.N., Pulka, Ch.V., Pismenny, A.S. (2003) Optimization of induction hardfacing of thin discs allowing for thermal and electromagnetic shielding. Ibid., 9, 20-23.

9. Pulka, Ch.V., Shably, O.N., Pismenny, A.S. (2004) Effect of induction surfacing conditions on structure and properties of deposited metal. Ibid., 10, 15-17.

10. Pulka, Ch.V., Shably, O.N., Senchishin, V.S. et al. (2012) Influence of vibration of parts on structure and properties of metal in surfacing. Ibid., 1, 23-25.

11. Pulka, Ch.V., Senchishin, V.S., Gavrilyuk, V.Ya. et al. (2013) Influence of technological schematics of induction surfacing on stability of deposited layer thickness. Ibid., 4, 61-63.

12. Shably, O.N., Pulka, Ch.V., Pismenny, A.S. et al. (1999) Residual displacements of thin steel discs in induction surfacing with wear-resistant powder-like hard alloys. Avtomatich. Svarka, 9, 55-57.

13. Shably, O.M., Mykhajlyshyn, M.S., Mykhajlyshyn, V.M. et al. (1998) Mathematical modeling of formation of residual stresses, strains and displacements in induction surfacing of thin steel discs. Visnyk TernopilDTU, 3(4), 5-12.

14. Shably, O.N., Pulka, Ch.V. (1994) Technology and equipment for induction surfacing of thin shaped discs. Avtomatich. Svarka, 5/6, 48-50.

15. Pulka, Ch.V., Gavrilyuk, V.Ya., Senchishin, V.S. (2013) Improvement of equipment and technology for induction surfacing. Svarochn. Proizvodstvo, 4, 27-30.

16. Pulka, Ch.V., Gavrylyuk, V.Ya., Senchyshyn, V.S. et al. Automatic production line for surfacing of thin discs. Pat. 94727 UA. Int. Cl. B23K 13/00. Publ. 25.11 .2014

Received 12.03.2015 